\title{
Taking the Long View: What Does a Child Focus Add to Social Protection?
}

\author{
Rachel Sabates-Wheeler, Stephen Devereux and \\ Anthony Hodges
}

\begin{abstract}
Recognising that many indicators of vulnerability among children, such as malnutrition or poor educational performance, might reflect intergenerational problems has profound implications for the design and implementation of social protection programmes. Treating the symptoms of these problems is of course essential: a malnourished child needs immediate nutritional support and a child who is failing at school needs special attention. But the argument of this paper is that 'taking the long view' is imperative if the reasons why children are malnourished, or failing, are to be correctly identified and adequately addressed. Importantly, the analysis implies directing interventions not exclusively at the children who are at risk, but at others in society who are responsible for the care of children.
\end{abstract}

\section{Introduction}

Our overarching objective is to reflect on how social protection for children requires 'thinking outside the box'. Child-sensitive social protection has a different remit from other mainstream social protection programmes for adults, as it must necessarily recognise the overwhelming evidence that vulnerabilities facing children differ from those facing adults. Recognising the ways in which deprivation and poverty are transmitted across generations and across time requires that social protection programmes take the long view, tackling multiple deprivations through protective as well as transformative agendas.

\section{Children and vulnerability}

Social protection, as an agenda primarily for reducing vulnerability and risk of low-income households with regard to basic consumption and services, has become an important part of the development discourse (Barrientos and Hulme 2008; Devereux and Sabates-Wheeler 2007). Social protection is commonly conceived in a narrow 'safety net' sense, as mechanisms for smoothing consumption in response to declining or fluctuating incomes. Such interventions are dominated by targeted food or income transfers to designated 'vulnerable groups', such as female-headed households, people with disabilities, or children (specifically orphans). These 'homogeneous' categories are useful for minimising the costs of targeting transfers, but they frequently under-predict and misdiagnose the range of vulnerabilities facing different groups. Nowhere is this more apparent than in the policy and programmatic prescriptions for tackling child poverty and vulnerabilities.

We take as our starting point the overwhelming evidence that vulnerabilities facing children differ from those of adults. Child-specific vulnerabilities derive from asymmetrical power relations and inequalities in relation to resources, responsibilities, opportunities, voice, rights and constraints. Vulnerabilities differ throughout the life cycle but are particularly pronounced within the foetus-baby-childadolescent age spectrum. Child-intensified vulnerabilities refer to those vulnerabilities that may affect whole populations, such as famine or undernutrition, but have effects that are more damaging for children than adults.

Child poverty and wellbeing are multidimensional. Children experience complex physical and intellectual development as they grow, and are more vulnerable to malnutrition, 
abuse and exploitation than adults. Their dependency on adults to support and protect them means that loss of family care is a significant risk, particularly in the context of conflict, humanitarian crises and AIDS. Intrahousehold discrimination can also result in hunger, lack of access to services, and abuse and exploitation of certain children. These risks may increase in situations where women's access to independent livelihoods is lower and the distribution of power and resources is highly inequitable, since women bear the greatest responsibility for childcare and protection. Inequality in physical strength and in information also means that children can be more easily exploited. Finally, by virtue of their age and 'minor' status in society, children are practically and legally less able to claim their rights. Even child-headed households are unable to voice their political preferences as they are not allowed to vote.

The asymmetry in vulnerabilities between children and adults implies that children are less able to make their vulnerabilities visible without support, less able to claim or negotiate their entitlements, and unable to take legal action in the case of abuse. Clearly, there is a compelling case to be made for strong and appropriate social protection for children. Social protection for various groups of vulnerable children typically assumes that the main source of vulnerability is economic poverty. However, as discussed by Sumner, Haddad and Gomez-Climent (in this IDS Bulletin) economic poverty is only one dimension of wellbeing, and perhaps not the most relevant when considering children's vulnerabilities. To the extent that children's vulnerabilities are related to intra-household inequalities in resource allocation and labour demands, targeting social protection interventions to children, without dealing with the intra-household constraints to resourcesharing, will do little to alleviate their vulnerability. A recent review of 17 national plans of actions (NPAs) for orphans and vulnerable children revealed that great emphasis was given to psychosocial counselling, which of course is often necessary; however, there was little that challenged or even investigated the structural vulnerabilities facing orphans and vulnerable children (OVC) and the factors that perpetuate these vulnerabilities (SabatesWheeler and Pelham 2006).
The typical 'lumping together' of different categories of children by social protection initiatives further explains the limited attention to structural vulnerabilities that emerge from and are exacerbated by exclusion, discrimination and stigmatisation. These issues are rarely made explicit within definitions or programming. Thus while many of the NPAs devote substantial textspace to the 'rights' of OVC as enshrined by legal frameworks and facilitated by sensitisation campaigns, there is little explicit reference to programmes focused on empowering the orphans themselves so that they can take proactive steps to access productive assets and claim rights as individuals.

\section{The long view: life course and generations}

Current approaches to social protection focus on provisions to assist households and individuals manage short-term income or consumption deficits, but this might be too narrowly conceived.

The ideas of life-course and the intergenerational transmission of poverty [and disadvantage] emphasise the linked set of processes that may result in, or entrench, childhood, adulthood or chronic poverty, rather than the outcomes of experiences during a specific period of time.

(Harper et al. 2003: 535)

The implication is that social protection needs to adopt a life-course and intergenerational perspective in order to promote sustainable improvements in wellbeing as well as breaking intergenerational transmissions of poverty. Within the social protection field it is rare that (1) children and their long-term needs are incorporated to achieve long-term positive and sustainable change for the children; and (2) the complex relationships between children, their caregivers and broader society are factored into programme design. In this section we draw on evidence that highlights the importance of taking the 'long view' to child vulnerability. We then think through the implications for the design of social protection measures.

\subsection{Intergenerational transmissions: parental education and the attainment gap ${ }^{1}$}

Bloom (1964) estimated that at least half the variance in cognitive development, as measured by IQ tests, is predictable from levels of 


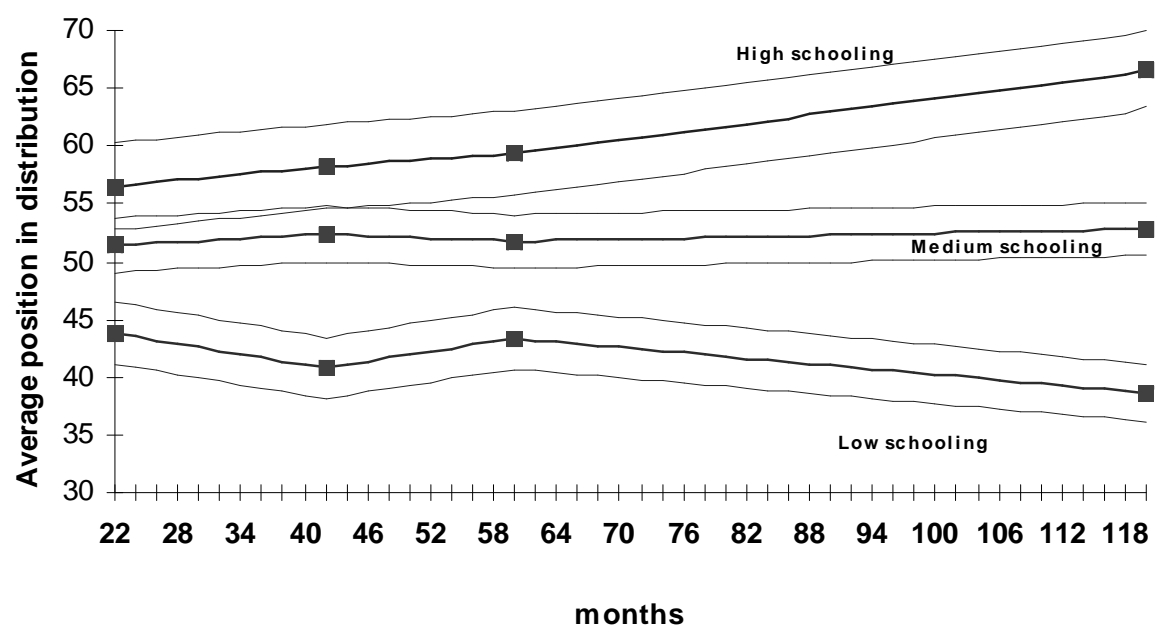

Dotted lines represent intervals of two standard errors. High schooling denotes families where both parents have A-level or higher (474 observations); low schooling denotes families where neither parent has qualifications (226 observations); medium schooling denotes those omitted from the high and low categories (592 observations).

Source Feinstein (2003: 73-98).

functioning in the first three years of life. The relationship between family social class and children's academic development has since been widely established and the premise is now accepted almost universally. Evidence for the UK indicates that the social class gradient becomes significant before children enter school (Feinstein 2003), suggesting that family contexts are particularly important in explaining educational disadvantage.

Social class is about much more than just education, but stratifying children's achievement by parental education, rather than by traditional occupational measures of social class, reveals that the gradient is just as steep. This is shown for children born in the UK in 1970. Figure 1 indicates that, already by 22 months, there is a significant difference in cognitive development. This difference not only persists over time but also gets worse. There is a widening gap that is explainable beyond genetics.

This suggests that the same common features underlie the attainment gap, however one stratifies parental background, and there is substantial evidence that children's education levels and cognitive development are positively related to the education of their parents (Wolfe and Haveman 2002). For example, whether parents left school before the age of 15 has a strong, negative correlation with the probability that the young person will stay on at school beyond the mandatory age (Bynner and Joshi 2002; Gregg and Machin 2000). Other evidence shows that mothers' educational qualifications are positively related to their children's school readiness, mathematics and reading test scores (Gayle et al. 2002; Joshi and Verropoulou 2000) and achievement of grades.

While evidence indicates that a proportion of the educational gap is genetic, social environment plays a crucial role in transmitting disadvantage. There is an obvious role for social protection programmes to intervene early to attempt to rectify this inequality.

\subsection{Inter-temporal transmissions: poor nutrition and stunting in childhood and development outcomes in adulthood}

Estimates using WHO global data indicate that one out of every three pre-schoolers in developing countries exhibits stunted growth (defined as height-for-age being two standard deviations below international norms) (de Onis and Blössner 2003). Stunting is a manifestation of chronic (long-term) malnutrition, and for this reason improving the nutritional status of preschoolers is fundamental to the achievement of several development goals. A causal relationship has been posited between nutritional status, 
acquisition of knowledge at school and height attained as adults. Positive and robust associations have also been established between schooling and productivity and height and productivity, implying that investment in children's nutrition has long-term pay-offs, both private and public (Behrman 1996; Leslie and Jamison 1990).

Alderman et al. (2006) attempt to study the causal pathways by which stunting may affect human capital outcomes later in life, by employing instrumental variables in a panel study from Zimbabwe. They also evaluate the extent to which recovery from stunting due to drought can occur by examining the impact of pre-school malnutrition on subsequent human capital formation. Their results show that improved pre-schooler nutritional status, as measured by height-for-age, is associated with increased height as a young adult, a great number of grades of schooling completed, and an earlier age at which the child starts school. They also show that lost growth velocity as a preschooler is only partially recovered subsequently. In other words, nutritional deprivation as a child has irreversible negative effects in adulthood. The same study found that older children did not suffer such consequences, confirming that children face heightened 'sensitive' periods in their development where external shocks will be more influential and will have longer-lasting impacts. Intervention early in the life course and at particular points, especially with respect to ensuring adequate nutrition in the event of shocks (e.g. drought) and stresses (e.g. resulting from chronic poverty), is crucial for reducing long-term deprivations.

\subsection{Pre-natal transmissions: poor nutrition of mothers and health gaps}

The number of children under five who are low weight-for-age or low height-for-age is steadily declining in most countries, but in sub-Saharan Africa the number is steadily increasing. In 1990, 80 out of every 100 underweight children lived in Asia and 16 in Africa, but by 2015 these numbers are projected to be 60 and 38 respectively, if recent trends continue (de Onis et al. 2004).

The 'foetal origins' hypothesis has recently provided traction for a number of empirical studies that attempt to trace the long-term development impact of the malnutrition of the foetus in utero (Gillespie and Haddad 2003; Behrman et al. 2004). As Behrman et al. report: 'a number of maternal factors have been shown to be significant determinants of intrauterine growth retardation (IUGR), the characterisation of a newborn who does not attain their growth potential'. Among these characteristics are the mother's (1) stature (reflecting her own poor nutritional health during childhood),

(2) nutritional status prior to conception (typically reflecting chronic poverty and lack of nutritional knowledge), (3) weight gain during pregnancy. Diseases, parasites, malaria and other infections - all of relatively high prevalence among poor groups in low-income countries - greatly contribute to IUGR.

A positive and robust correlation between poor nutritional status in children and low birthweight (LBW) has been established by a range of studies (Ashworth et al. 1997; Hoddinott and Kinsey 2001). The relationship sits at the heart of the foetal origins hypothesis and provides support to an increasing body of evidence that many nutritional outcomes are the consequence of cumulative life-cycle processes. Maternal malnutrition leads directly to low birth-weight and subsequent poor child nutrition, which in turn is strongly related to stunted body size, cognitive impairment, poor educational performance, poorer psychosocial development, lower activity levels, and a failure to acquire skills at normal rates (for evidence of these effects see Behrman et al. 2004). Thus maternal malnutrition has long-term consequences through the transmission of nutritional deprivation and restricted life prospects for her children.

The evidence from the range of studies discussed above indicates that early intervention in child development - whether directed at the carrier, carer or child - is crucial for future attainment of nutritional, health and educational status.

However, many such programmes have been implemented globally (nutritional supplements for pregnant mothers, school feedings, training programmes for carers, for instance) with little impact on aggregate outcomes, particularly in Africa. We would argue that this conundrum is largely explained by a failure to recognise the structural problems that cause deprivation to persist, and become entrenched, over time. In other words, acting to break the cycle of 
Figure 2 Child mortality by wealth quintiles: Africa and the rest of the world (ratio of different quintiles' U5MR to lowest quintile's U5MR; based on wealth index)
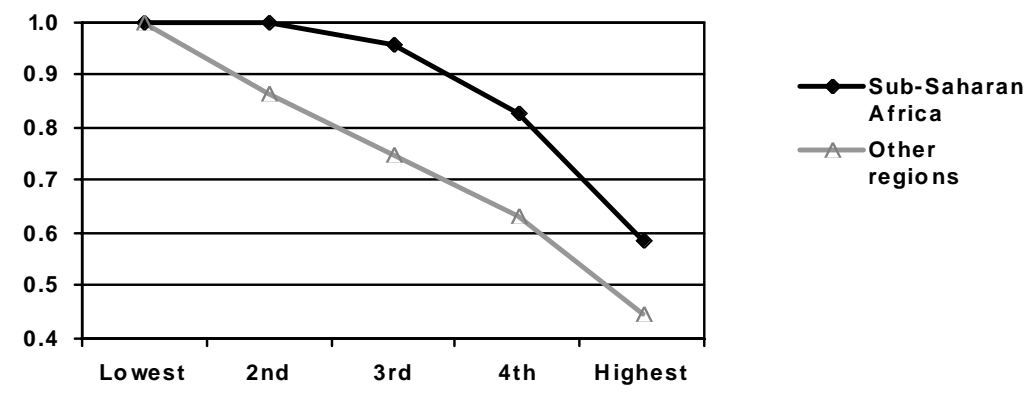

Source Tibouti (2008).

intergenerational transmission requires more than medical and nutritional interventions; it also requires attention to the nature of structural inequalities. We discuss this now.

\subsection{Persistent inertia in the distribution of deprivation}

In much of Africa, the transmission processes discussed above do not affect only a small, marginalised component of the population. Most sub-Saharan African countries are characterised by what might be described as 'top inequity', where a small minority is much better off than the broad mass of the population. (This contrasts with a situation of 'bottom inequity', where a small minority is much worse off than everyone else.) Broadly speaking, sub-Saharan African countries demonstrate 'top inequity' in terms of monetary poverty and many other indicators of deprivation. Income and consumption expenditure levels rise only very gradually through the bottom five to six deciles, and in many countries over half of the population live below the absolute poverty line. This is mirrored by the relationship between monetary poverty and child deprivations. Data from Demographic and Health Surveys (DHS), using a wealth index as a proxy for monetary poverty, demonstrate a clear relationship between household assets and child indicators, but one in which there is only a small difference in child wellbeing in the bottom three quintiles. This contrasts with the situation in most other regions of the world, as can be seen from the following two examples.

The first, on child mortality, shows the ratio of under-five mortality rates (U5MR) in each wealth quintile with the U5MR for the lowest quintile, contrasting sub-Saharan Africa with other regions. Tibouti (2008) has shown how the U5MR in sub-Saharan Africa is almost as high in the second and third quintiles as in the lowest quintile - a stark contrast with the situation elsewhere (see Figure 2).

Figure 3 Percentage of children under five receiving six or more health interventions: Benin and Brazil

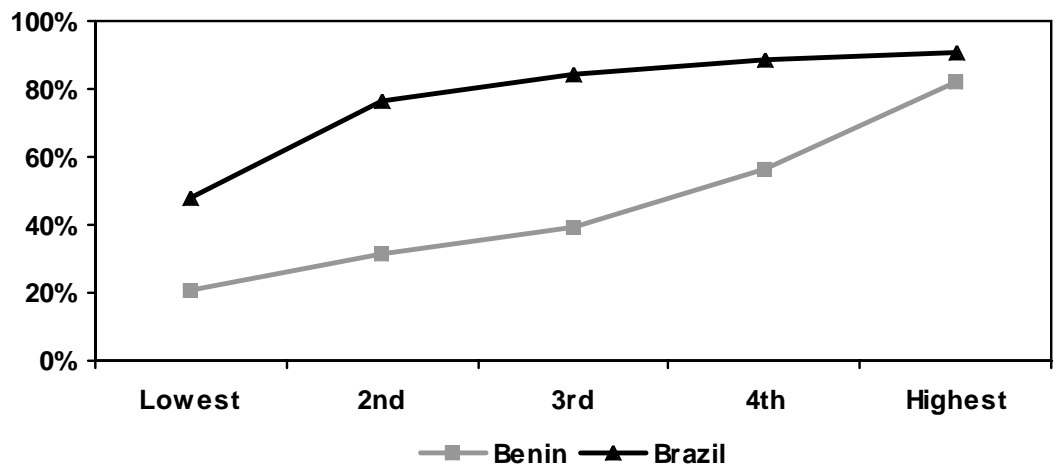

Source Victoria et al. (2005). 
Figure 4 Pupil-teacher ratio in primary education, 2004

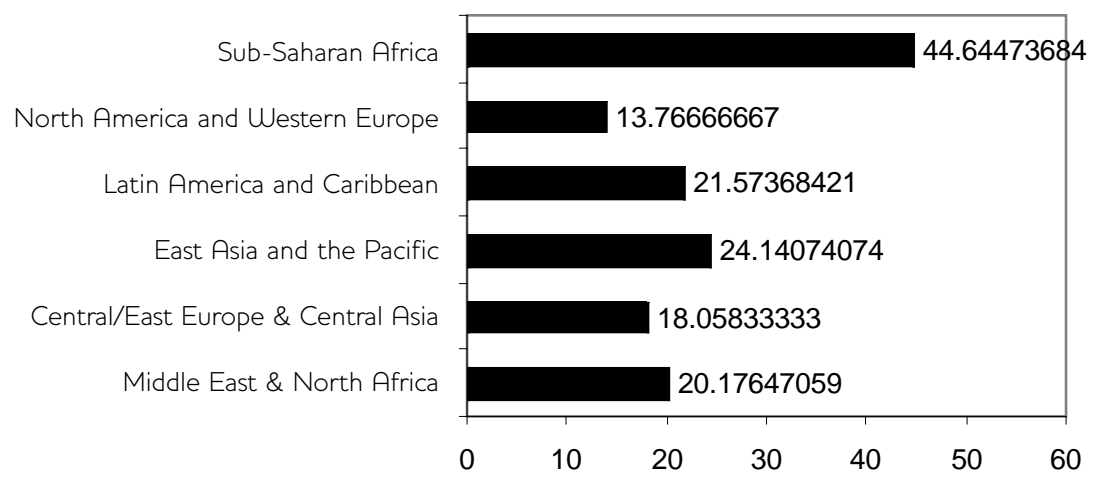

Source UNESCO (2005).

The second example contrasts the access of children under the age of five to key health interventions between Benin in West Africa, and Brazil in South America (see Figure 3). As can be seen, the curve is almost flat in Brazil except for the first quintile, where health service deprivations are much worse than for all the other quintiles, whereas in Benin deprivations diminish only gradually between the first and third quintiles and then rise more steeply, especially in the fifth quintile (Victora et al. 2005).

The key policy implication is that, to have a significant impact on children's access to health services and child mortality and thus accelerate progress towards Millennium Development Goal (MDG) 4, it is necessary to focus across the first three or even four quintiles. A narrower, more finely targeted approach (say on the bottom 20 per cent) will make only a modest contribution to addressing the full extent of the problem.

In education, universal approaches enjoy a wide consensus, although many African countries have not yet implemented free primary education in practice. In health, where user fees were introduced in the 1980 s and are still widely practised, there is growing recognition of the barriers they constitute for access to health services. The main obstacles cited by women in accessing health services in West and Central Africa are finding the money for treatment (54.7 per cent), distance to health facilities (38.5 per cent) and having to take transport to reach health services (36.2 per cent), according to DHS data (ODI 2008). This has led some African governments to establish national health insurance schemes, although the requirement to pay premiums may prove an obstacle to enrolment by the poor (in Ghana enrolment had reached 42 per cent of the population by mid2008). Several governments have taken the simpler, tax-based route of abolishing fees for specific maternal and child health services, or for children under the age of five, and Ghana has complemented its National Health Insurance Scheme by abolishing all health service fees for children under 18 and pregnant and post-partum women, since May 2008 (Jones et al. 2008).

The extensive nature of deprivations in much of Africa does not only reflect the small difference in income levels between households in the bottom five to six deciles. It is also related to serious supply-side shortfalls in the provision of basic social services, which again contrasts with the situation in other parts of the world. Human resources in education and health systems provide a good proxy measure for this. Figure 4, using data from UNESCO, shows that the pupil-teacher ratio in primary education in subSaharan Africa is more than double the ratio in Latin America. There are similar discrepancies in the numbers of doctors, nurses and other health workers.

This raises questions about the appropriateness of focusing on demand-side access barriers, as well as the use of 'conditional cash transfers'. In Latin America, cash transfers accompanied by conditionalities in terms of school attendance, vaccinations and child-growth monitoring have been used extensively to promote human capital investment in children, by overcoming cost barriers to basic social services (fees, transport costs, opportunity costs). These programmes 
have been widely hailed for raising school attendance, curbing school dropouts and improving health and nutrition outcomes (see, for example, Rawlings and Rubio 2004). But is this approach appropriate in those African countries (or regions within countries) that have huge deficits in both the availability and quality of basic social services? The question is particularly pertinent in countries with limited fiscal space and a need to make tough decisions about priorities and trade-offs in the use of public resources. Conditional cash transfers would seem to be misplaced in countries with such supply-side deficits, although it is being trialled in some social protection interventions in Africa, such as Ghana's Livelihood Empowerment Against Poverty (LEAP) programme (Sultan and Schrofer 2008).

These findings highlight the variety of time- and scale-related transmissions of deprivation that can occur and that impact negatively on children. Social protection needs to take stock of this knowledge and intervene to support parents and carers to break intergenerational transmission, as well as work quickly to minimise the irreversible long-term impacts from sudden shocks. However, as the evidence from Africa shows, some of these problems are structural, reflecting the extent of monetary poverty and child deprivations, as well as serious supply-side deficits in the provision of basic social services for children. Other problems are sociocultural, requiring changes in gender relations and deep-seated attitudes, as well as anti-discrimination legislation and other 'transformative' measures to overcome the social exclusion of ultra-vulnerable marginalised groups.

\section{Tackling structural vulnerability: implications for design and implementation}

Many sources of vulnerability facing children are not exogenous but are socially constructed.

Failure to understand the social dimensions of vulnerability leads to persistent misdiagnosis of the problem as entirely economic (e.g.

household-level poverty) and therefore as being amenable to economic transfers (e.g. food aid to alleviate hunger, or cash transfers to support household income growth). These interventions are important to reduce household food insecurity, and they can have sustainable impacts on poverty reduction. But are they the most effective instruments to address all the diverse sources of vulnerability that children face? This article concludes by discussing three alternative approaches that take a different view.

\subsection{Transformative social protection for children}

Recognising that many indicators of vulnerability among children, such as malnutrition or poor educational performance, might reflect intergenerational problems has profound implications for the design and implementation of social protection programmes. Treating the symptoms of these problems is of course essential: a malnourished child needs immediate nutritional support and a child who is failing at school needs special attention. But the argument of this article is that 'taking the long view' is imperative if the reasons why children are malnourished, or failing, are to be correctly identified and adequately addressed.

'Transformative social protection' (TSP) (Sabates-Wheeler and Devereux 2008) is an approach that has great potential to 'take the long view' on social protection for children. TSP differs from other approaches because it looks beyond the manifestations of vulnerability to the underlying structural causes of vulnerability, with a view to identifying a complementary set of interventions that aim to transform the initial conditions that generate vulnerability and deprivation. TSP argues that social protection should not be restricted to the delivery of social services and transfers to vulnerable individuals, but should also include measures to modify or regulate behaviour towards socially vulnerable groups. This implies 'transforming society' to redress power inequalities that result in discrimination and social exclusion. Children are especially vulnerable in this regard, because they have little voice and are either in the care of others or have no one caring for them, each of which raises its own challenges.

A 'transformative' approach to addressing the vulnerabilities of children requires a longer time perspective and a broader frame of reference than the children themselves. It requires looking intergenerationally, at events that occurred in the lives of the parents before the child was born, and it requires examining the behaviour of parents and carers, as individuals and as members of societies with particular cultural attitudes, values and norms of behaviour, not all of which are necessarily in the best interests of all children. 
Consider, for example, cases where girl children are systematically discriminated against within families, because of cultural norms that privilege males in intra-household allocations of food, childcare and access to health and education services. What then is the appropriate role for social protection? Gender bias is a welldocumented problem across the world, and its implications are profound. Amartya Sen estimated that gender bias is responsible for more than 100 million 'missing women' globally.

Because of 'gender bias' against women in many parts of the world, women receive less attention and care than men do, and particularly girls often receive very much less support than boys. As a result, the mortality rates of females often exceed those of males in these countries.(Sen 1998: 12)

If parental neglect of girls is responsible for such fundamental differentials in gendered wellbeing outcomes, then standard approaches to social protection are inadequate at best and counterproductive at worst. Cash or food transfers delivered to the household might not reach girl children, even if this is the intention, and could reinforce established gendered disparities. Girls will not receive their fair share of food aid, and they will not benefit from any improvements in household income that cash transfers might generate - at best their wellbeing will lag consistently behind their brothers'.

Providing effective protection to girls in such circumstances requires intervening at the source of the problem, in this case, attitudes and norms that are prejudicial to girls' wellbeing.

Appropriate interventions could include gender sensitisation campaigns for parents, training of public service providers to devote equal time and resources to male and female patients at clinics and learners at schools, inclusion of gender awareness in schools and adult learning curricula, even legislative change to outlaw systematic discrimination against women and girls (in terms of inheritance rights, rights to own land or open bank accounts, female genital mutilation, early marriage, and so on).

Importantly, this analysis implies directing interventions not exclusively at the children who are at risk, but also at others in society who are responsible for the care of children - mothers, fathers, teachers, nurses, etc. As seen above, one of the most effective interventions to enhance the physical growth and cognitive development of children is to invest in the nutrition of adolescent girls and to change attitudes towards early marriage, to reduce the numbers of young mothers who give birth to low birth-weight babies. The pay-off to such interventions is on multiple levels. Girl children will be better treated from birth (or even before, if female infanticide and gender-selective abortions can be eliminated). Programmes designed to benefit girls and women will be more likely to reach them. The need for 'safety nets' to support children and others affected by discriminatory practices and norms will decline, releasing public resources that can be more effectively invested, for instance in health and education services.

\subsection{Legalising children: birth registration as social protection}

We have argued above that 'transformative social protection' emphasises the need to change the circumstances of people's lives that generate structural vulnerabilities. In many cases, this requires intervening at the level of legislative reform. In the case of children, attaining a legal status is a crucial determinant of their future life prospects. People's ability to participate in society is profoundly affected by their registration and citizenship status. Registration defines legal identity, which in turn determines the right of citizens to claim entitlements to public services and social grants from the state, and their right to vote in democratic societies to remove governments that do not address their needs. Szreter (2007) notes that the human right to an identity is fundamental to enabling individuals to exercise a range of legal rights, including property rights and legitimate claims to social security.

The right of children to identity registration is enshrined in Article 7 of the UN Convention on the Rights of the Child (CRC) of 1990, which has now been ratified by all countries except Somalia and the USA. 'The child shall be registered immediately after birth and shall have the right from birth to a name' (www2.ohchr.org/english/ law/crc.htm). The CRG recapitulates a right first enshrined in the UN International Covenant on Civil and Political Rights (ICCPR) of 1966.

An important point which is implicit in Szreter (2007) is that identity registration is for life. The 
simple act of registering a birth has implications for the child's legal status and a range of associated rights that will persist from cradle to grave. In South Africa's social grants system, for instance, proof of identity is a prerequisite to secure access to Child Support Grants for young children, Old Age Pensions for older citizens, and a range of benefits in between. In fact, this need to verify identity and legal status is required by social security systems throughout the world. So birth registration is not just an abstract 'moral' right, it has tangible implications for access to social protection that the child will be entitled to claim throughout his or her life.

\subsection{Child-sensitive social protection}

Children are central in strategies for breaking the intergenerational transmission of deprivation. This article has argued that, due to their age and dependency status, children are more vulnerable than adults and are subject to a range of economic and social risk factors, which reinforce each other in complex ways. In addition to violating child rights in an immediate sense, deprivations in childhood have life-course consequences, increasing the likelihood that they will remain poor in adulthood and that their own children will be born and raised in an environment of disadvantage. This is one of the main arguments for investment in children from a human capital development perspective, as a means of breaking out of chronic poverty traps. For these reasons and others, including recognition of the potential role of social protection in accelerating progress towards the child-focused MDGs, there is growing awareness of the importance of placing children at the heart of social protection programming. This has been reflected recently in the drafting of a joint statement by a number of international development agencies, non-governmental organisations and research institutes, on 'childsensitive social protection' (UNICEF et al. 2008).

This statement, along with work by researchers for the Better Care Network and the

\section{Note}

1 This section draws on Feinstein et al. (2008).
International Task Team on Children and HIV and AIDS (Giese 2007; Temin 2008; IATT 2008), emphasises the social nature of the risks faced by vulnerable children, highlighting in particular the risks associated with the loss of family, notably in countries with high HIV and AIDS prevalence or armed conflicts. The main conclusion is the need for an integrated approach to social protection that addresses the multiple dimensions of child vulnerability. Different types of intervention are needed: protective and responsive services and legislation as well as transfers and insurance. In particular, specialised social welfare services are needed to reach children who are particularly vulnerable due to problems of abuse, exploitation and discrimination, or the breakdown or loss of family, as well as legislation and communication strategies to combat gender and ethnic discrimination and other sociocultural attitudes and practices that are harmful to children.

From this perspective, there are dangers in the current tendency among some development practitioners to reduce social protection to an almost exclusive focus on cash transfers, without giving adequate attention to the development of social welfare services, legislation and communication. An integrated approach is needed to exploit opportunities for complementarity and synergies between cash transfers, social welfare services, legislation and communication for development. Social welfare services can be strengthened, for example, to ensure that cash transfers reach the poorest and most vulnerable children, enhance child protection outcomes and avoid perverse incentives, such as the fostering of children for financial gain. An integrated approach means developing comprehensive national social protection strategies, rather than piecemeal approaches, and applying a holistic approach to capacity building, to strengthen ministries that are responsible for a range of benefit programmes and services. 


\section{References}

Alderman, Harold; Hoddinott, John and Kinsey, Bill (2006) 'Long Term Consequences of Early Childhood Malnutrition', Oxford Economic Papers Advance Access, originally published online on 2 May, Oxford Economic Papers 58.3: 450-74; doi: 10.1093/oep/gpl008

Ashworth, A.; Morris, S. and Lira, P. (1997) 'Postnatal Growth Patterns of Full-term Low Birthweight Infants in Northeast Brazil are Related to Socioeconomic Status', Journal of Nutrition 127.10: 1950-6

Barrientos, A. and Hulme, D. (eds) (2008), Social Protection for the Poor and Poorest: Concepts, Policies and Politics, Basingstoke: Palgrave Macmillan

Behrman, Jere (1996) 'The Impact of Health and Nutrition on Education', World Bank Research Observer 11: 23-37

Behrman, J.; Alderman, H. and Hoddinott, J. (2004) Hunger and Malnutrition, Copenhagen Consensus Challenge Paper

Bloom, B. (1964) Stability and Change in Human Characteristics, New York: John Wiley

Bynner, J. and Joshi, H. (2002) 'Equality and Opportunity in Education: Evidence from the 1958 and 1970 Birth Cohort Studies', Oxford Review of Education 28.4: 405-25

de Onis, M. and Blössner, M. (2003) 'The World Health Organisation Global Database on Child Growth and Malnutrition: Methodology and Applications', International Journal of Epidemiology 32: 518-26

de Onis, M.; Blössner, M.; Borghi, E.; Frongillo, E. and Morris, R. (2004) 'Estimates of Global Prevalence of Childhood Underweight in 1990 and 2015',JAMA 291.21, 2 June: 2600-6 (reprinted) American Medical Association Devereux, S. and Sabates-Wheeler, R. (2007) 'Debating Social Protection', IDS Bulletin 38.3

Feinstein, L. (2003) 'Inequality in the Early Cognitive Development of British Children in the 1970 Cohort', Economica 70.277: 73-97

Feinstein, L.; Duckworth, K. and Sabates, R. (2008) 'Education and the Family: Passing Success Across Generations', in Peter Aggleton and Sally Power (eds), Foundations and Futures of Education, Oxford: Routledge

Gayle, V.; Berridge, D. and Davis, R. (2002) 'Young People's Entry into Higher Education: Quantifying Influential Factors', Oxford Review of Education 28.1: 5-20

Giese, S. (2007) 'The Role of Social Services in Social Protection: Towards a Policy-Relevant
Research Agenda', paper commissioned by the Better Care Network, London: Better Care Network

Gillespie, S. and Haddad, L. (2003) The Double

Burden of Malnutrition in Asia: Causes, Consequences and Solutions, New Delhi: Sage Publications

Gregg, P. and Machin, S. (2000) 'The

Relationship Between Childhood Experiences, Subsequent Educational Attainment and Adult Labour Market Performance', in K. Vleminckx and T. Smeeding (eds), Child Well Being in Modern Nations: What Do We Know?, Bristol: Policy Press

Haveman, R. and Wolfe, B. (1995) 'The Determinants of Children's Attainments: A Review of Methods and Findings', Journal of Economic Literature 23: 1829-78

Hoddinott, J. and Kinsey, B. (2001) 'Child Growth in the Time of Drought', Oxford Bulletin of Economics and Statistics 63.4: 409-36

IATT (Inter-Agency Task Team on Children and HIV and AIDS) (2008) Social Protection for Vulnerable Children in the Context of HIV and $A I D S$, Working Paper, Working Group on Social Protection, IATT, Geneva: UNICEF

Jones, N.; Ahadzie, W. and Doh, D. (2008) 'Social Protection for Children: Opportunities and Challenges in Ghana', draft report for UNICEF West and Central Africa Regional Office, London: Overseas Development Institute

Joshi, H. and Verropoulou, G. (2000) Maternal Employment and Child Outcomes, Occasional Paper, London: Smith Institute

Leslie, Joanne and Jamison, Dean (1990) 'Health and Nutrition Considerations in Education Planning. 1. Educational Consequences of Health Problems Among School-age Children', Food and Nutrition Bulletin 12: 191-203

ODI (Overseas Development Institute) (2008) 'Alternative Social Health Protection in West and Central Africa: Achieving Equitable Access to Health Care and Reducing Child and Maternal Mortality', draft report for UNICEF West and Central Africa Regional Office, London: Overseas Development Institute

Rawlings, L.B. and Rubio, G.M. (2005)

'Evaluating the Impact of Conditional Cash Transfer Programmes', The World Bank Research Observer 20.1: 29-55

Sabates-Wheeler, R. and Devereux, S. (2008), 'Transformative Social Protection: The 
Currency of Social Justice', in A. Barrientos and D. Hulme (eds), Social Protection for the Poor and Poorest: Concepts, Policies and Politics, Basingstoke: Palgrave Macmillan

Sabates-Wheeler, R. and Pelham, L. (2006) Social Protection and OVC Policy: How do National Plans of Action for OVC Engage with the Social Protection Agenda?, UNICEF report

Sen, A. (1998) 'Mortality as an Indicator of Economic Success and Failure', The Economic Journal 108.446: 1-25

Sultan, S. and Schrofer, T. (2008) 'Building Support to Have Targeted Social Protection Interventions for the Poorest - the Case of Ghana', paper for the Conference on 'Social Protection for the Poorest in Africa: Learning from Experience', Entebbe, Uganda, 8-10 September

Szreter, S. (2007) 'The Right of Registration: Development, Identity Registration, and Social Security - A Historical Perspective', World Development 35.1: 67-86

Temin, M. (2008) Expanding Social Protection for Vulnerable Children and Families: Learning from an Institutional Perspective, Working Paper, InterAgency Task Team (IATT) on Children and HIV and AIDS: Working Group on Social
Protection, www.unicef.org/aids/files/ Expanding_Social_Protection.MTemin.May20 08.pdf

Tibouti, A. (2008) 'Disparities in Child Health: Preliminary Findings from MICS and DHS', presentation to Health Equity Consultation, UNICEF, New York, 4-6 February

UNESCO (2005) www.unesco.org/en/education/ efareport/reports/2005-quality

UNICEF et al. (2008) 'Advancing Child Sensitive Social Protection. Joint Statement of Governments, International organisations and Research Bodies concerned with Social development and Child Rights', draft report 28 July 2008, Geneva: UNICEF

Victora, C.; Fenn, B.; Bryce, J. and Kirkwood, B. (2005) 'Co-coverage of Preventive Interventions and Implications for ChildSurvival Strategies: Evidence from National Surveys', The Lancet 366.9495: 1460-6

Wolfe, B. and Haveman, R. (2002) 'Social and Non-market Benefits from Education in an Advanced Economy', paper presented at the 'Education in the 21st Century: Meeting the Challenges of a Changing World', Federal Reserve Bank of Boston (Conference Series 47), Boston, MA, 2002 